\title{
TEMPERATURE REGIME AND MALARIA CASES IN ORLU AREA OF IMO STATE NIGERIA
}

\author{
Fidelis Chinazor Okorie \\ Department of Geography and Environmental \\ Management, \\ Imo State University, Owerri, Nigeria. \\ E-mail: chinazorfiddy@ hotmail.com
}

\author{
Austine O. Nnaji \\ Department of Environmental Technology, \\ Federal University of Technology, Owerri, Nigeria. \\ E-mail: drnnaji@yahoo.com
}

\author{
Cyprain E. Ezedike \\ Department of Geography and Environmental Management, \\ Imo State University, Owerri, Nigeria
}

\begin{abstract}
The earth's climate is becoming increasingly warmer, most likely due to increasing greenhouse gas emissions. Climate variation is driven by uneven distribution of solar heating, the individual responses of the atmosphere, oceans and land surface, the interactions between these and the physical characteristics of the regions. Climate, more especially temperature has a strong and direct influence on development, reproduction and survival of tropical insects such as mosquitoes. Insect population growth potentials are mainly temperature driven, so a rise in temperature may either increase or decrease insect development. This paper highlights the influence of temperature on malaria cases in Orlu Macro-climate in Imo state of Nigeria. It employed the use of 20 years (1991-2010) temperature data of Orlu from Nigerian Meteorological agency and 20 years data on malaria cases in Orlu collected from the (9) nine health centers located within Orlu Local Government Area. In the correlation analysis, adopting Pearson's correlation coefficient method, there was stability in high temperature regime with stable increases in malaria cases. Therefore, the results show that more than $50 \%$ of the malaria cases were, influenced by increase in temperature in the area. This means that temperature enhances mosquito breed, which causes spread of malaria in the environment. Hence, evidence of climate variability in Nigeria includes increasing heat waves, which enhances disease vectors, communicable diseases and epidemics. However, the people try to prevent the spread of malaria in the environment to some extent, but the study suggested more measures that are preventive.
\end{abstract}

\section{INTRODUCTION:}

Scientists over the years have conclusively projected that climate change would continue to change the range of some infections disease vectors, IPCC [2007].

Malaria is one of the most common infectious diseases and a great public health problem worldwide, particularly in Africa and South Asia.

Malaria kills above one million people every year, mainly in tropical Africa, and debilitates up to four hundred million others, WHO [2007]. This disease (malaria) is caused by protozoans from the genus plasmodium, which is transmitted from person to person by mosquitoes from the Anopheles genus. Scientists however believe that climate is one major determinant of malaria distribution in Africa, largely because both vectors and protozoa prefer warm, humid conditions, which enables them breed and multiply faster. The vast majority of malaria death occurs in Africa, South of the Sahara, where malaria also presents major obstacles to social and economic development.
Mosquitoes are very sensitive to temperature changes. Warming of their environment within their viable range boots their rates of reproduction, and the number of bloodmeals they take prolongs their breeding season and shortens the maturation period for the microbes they disperse.

Malaria is alleged to be the most common serious infections disease worldwide. It is predominantly a disease of warm climates, but $41 \%$ of the world's population live in endemic areas, WMO [1995].

Malaria is on the increase in world at large, but particularly in Africa, where climate, more especially temperature has a strong and direct influence on development, reproduction and survival of tropical insects such as mosquitoes, Okorie et al. [2012].

UNICEF [2009] observed that in Nigeria, malaria causes the deaths of an estimated 250,000 children under the age of five every year.

Malaria is a threat to many lives in the tropical climates, hence this research focuses on the relationship between temperature and malaria incidence in Orlu area of Imo State in the southeastern Nigeria.

\section{BACKGROUND INFORMATION OF THE STUDY AREA:}

According to geological records, Orlu in Imo State of Southeastern Nigeria is within a sedimentary rock formation and lies within the Awka-Orlu uplands in a zone of sandy lateritic soil. It has a population of 143,717 persons (National Population Commission, 2006). The climate is a typical humid climate, the same in the Southeastern region of Nigeria. Two distinctive seasons are familiar with the climate of the area. The rainy season, that begins in April and ends in October, with higher intensity in June and July, and late September, and dry season which begins in November and ends in March. The annual amounts of rainfall vary between $1,990 \mathrm{~mm}$ and $2,200 \mathrm{~mm}$. Temperature characteristics are generally high with little variation during the year. The mean daily maximum air temperature ranges from 230 - 280c, while the mean daily minimum values rang from $200 \mathrm{c}$ to $260 \mathrm{c}$. This shows that Orlu receives abundant and relatively constant solar radiation because of its latitudinal location, being bisected by the $5^{0}$ parallel.

\section{MATERIALS AND METHODS}

Twenty years (1991-2010) temperature data of Orlu, Imo State acquired from Nigerian Meteorological Agency, Lagos was used as well as data on malaria cases collected from 9 different health centers located within Orlu, 
including Government maternity, Umuna; Eziachi health Centre; Owerre-Ebeiri health centre; Okwuabala health centre; Umuowa health centre; Umutanze health centre; Acharaba health centre, Ogberuru; Ndiowa health centre, Orlu town; and Model Primary HealthCare centre, at Ofeahia. The data on malaria cases for the same period (1991-2010) was acquired from Roll-back-malaria department, Imo State Ministry of Health, Orlu area office.

The two research variables (data) were put together as shown on the table 1 below to draw a correlation between the climate factor (temperature) and the social factor (malaria cases).

TABLE 1: TWENTY YEARS TEMPERATURE CONDITIONS AND MALARIA CASES IN ORLU, NIGERIA (1991- 2010)

\begin{tabular}{|l|l|l|l|l|l|l|}
\hline S/N & Year & $\begin{array}{c}\text { Mean } \\
\text { Min } \\
\text { Temp. } \\
{ }^{\circ} \mathrm{C}\end{array}$ & $\begin{array}{c}\text { Mean } \\
\text { Max } \\
\text { Temp } \\
.{ }^{\circ} \mathrm{C}\end{array}$ & $\begin{array}{c}\text { Average } \\
\text { Temp. } \\
{ }^{\circ} \mathrm{C}\end{array}$ & $\begin{array}{c}\text { Total } \\
\text { Malaria } \\
\text { Cases }\end{array}$ & $\begin{array}{c}\text { Ave. } \\
\text { Malaria } \\
\text { Case }\end{array}$ \\
\hline 1. & 1991 & 23.5 & 31.6 & 28.0 & 3,661 & 305.1 \\
\hline 2. & 1992 & 22.9 & 31.7 & 27.3 & 3,925 & 327.1 \\
\hline 3. & 1993 & 22.3 & 31.7 & 27.4 & 4,348 & 362.3 \\
\hline 4. & 1994 & 22.3 & 31.8 & 27.1 & 4,009 & 334.1 \\
\hline 5. & 1995 & 22.4 & 31.9 & 27.2 & 4,522 & 376.8 \\
\hline 6. & 1996 & 23.0 & 32.5 & 28.0 & 4,496 & 374.7 \\
\hline 7. & 1997 & 23.5 & 32.3 & 28.0 & 4,306 & 358.8 \\
\hline 8. & 1998 & 23.6 & 33.1 & 28.4 & 4,476 & 373 \\
\hline 9. & 1999 & 23.7 & 31.8 & 28.0 & 4,580 & 381.7 \\
\hline 10. & 2000 & 23.6 & 32.2 & 28.0 & 4,319 & 359.9 \\
\hline 11. & 2001 & 23.8 & 32.2 & 28.1 & 3,884 & 323.7 \\
\hline 12. & 2002 & 23.7 & 32.3 & 28.0 & 4,323 & 360.3 \\
\hline 13. & 2003 & 24.1 & 32.4 & 28.3 & 4,314 & 359.5 \\
\hline 14. & 2004 & 28.9 & 32.4 & 30.7 & 4,359 & 363.3 \\
\hline 15. & 2005 & 24.1 & 32.8 & 29.0 & 4,542 & 378.5 \\
\hline 16. & 2006 & 24.3 & 32.9 & 29.0 & 4,404 & 367 \\
\hline 17. & 2007 & 22.2 & 31.7 & 27.0 & 4,300 & 358.3 \\
\hline 18. & 2008 & 23.7 & 32.7 & 28.2 & 4,326 & 360.5 \\
\hline 19. & 2009 & 22.7 & 31.5 & 27.1 & 4,159 & 346.6 \\
\hline 20 & 2010 & 23.7 & 31.8 & 28.0 & 7,100 & 591.7 \\
\hline Source & $0 f$ Data. & Nigen \\
\hline
\end{tabular}

Source of Data: Nigeria Meteorological Agency (NIMET) Lagos 2011, and Ministry of Health, Orlu Health Centre Imo State, 2013.

\section{RESULTS AND DISCUSSION}

\section{A. Results}

\section{Correlation analysis}

$\mathrm{X}$ is Temperature regime (climate factor), being an independent variable while $\mathrm{Y}$ is Malaria cases (social factor), and a dependent variable (table 2). Therefore $\mathrm{Y}$ is dependent upon $\mathrm{X}$. that is average temperature versus average malaria cases.
TABLE 2: STATISTICAL TABLE FOR COMPUTING THE CORRELATION BETWEEN X AND Y VARIABLES.

\begin{tabular}{|l|l|l|l|l|l|}
\hline $\mathrm{S} / \mathrm{N}$ & \multicolumn{1}{|c|}{$\mathrm{X}$} & \multicolumn{1}{|c|}{$\mathrm{Y}$} & \multicolumn{1}{|c|}{$\mathrm{X}^{2}$} & \multicolumn{1}{|c|}{$\mathrm{Y}^{2}$} & \multicolumn{1}{c|}{$\mathrm{XY}$} \\
\hline 1. & 28.0 & 305.1 & 784 & 93,086 & $8,542.8$ \\
\hline 2. & 27.3 & 327.1 & 745.3 & $106,994.4$ & $8,929.8$ \\
\hline 3. & 27.4 & 362.3 & 750.8 & $131,261.3$ & $9,927.0$ \\
\hline 4. & 27.1 & 334.1 & 734.4 & $111,622.8$ & $9,054.1$ \\
\hline 5. & 27.2 & 376.8 & 739.8 & $141,978.2$ & $10,248.96$ \\
\hline 6. & 28.0 & 374.7 & 784 & $140,400.1$ & $10,491.6$ \\
\hline 7. & 28.0 & 358.8 & 784 & $128,737.4$ & $10,046.4$ \\
\hline 8. & 28.4 & 373 & 806.6 & 139,129 & $10,593.2$ \\
\hline 9. & 28.0 & 381.7 & 784 & $145,694.9$ & $10,687.6$ \\
\hline 10. & 28.0 & 359.9 & 784 & 129,528 & $10,077.2$ \\
\hline 11. & 28.1 & 323.7 & 789.6 & $104,781.7$ & $9,095.97$ \\
\hline 12. & 28.0 & 360.3 & 784 & $129,816.1$ & $10,088.4$ \\
\hline 13. & 28.3 & 359.5 & 800.9 & $129,240.3$ & 10.173 .9 \\
\hline 14. & 30.7 & 363.3 & 942.5 & $131,986.9$ & $11,153.3$ \\
\hline 15. & 29.0 & 378.5 & 841 & $143,262.3$ & $10,976.5$ \\
\hline 16. & 29.0 & 367 & 841 & 134,689 & 10,643 \\
\hline 17. & 27.0 & 358.3 & 729 & $128,378.9$ & $9,674.1$ \\
\hline 18. & 28.2 & 360.5 & 795.2 & $129,960.3$ & $10,166.1$ \\
\hline 19. & 27.1 & 346.6 & 734.4 & $120,131.6$ & $9,392.86$ \\
\hline 20 & 28.0 & 591.7 & 784 & $350,108.9$ & $16,567.6$ \\
\hline $\mathcal{E}$ & 560.8 & $7,362.9$ & $15,738.5$ & $2,770.788 .1$ & $206,530.4$ \\
\hline$N$ & $20,1$. & $t h e n u m b$ & $0 f$ & & \\
\hline
\end{tabular}

$\mathrm{N}=20$, i.e. the number of years (1991-2010)

The formula for computing the Pearson's correlation coefficient is

$$
\begin{aligned}
& r=\varepsilon X Y-\varepsilon X E Y \\
& \sqrt{\frac{N}{\left.\left(E X^{2}-\frac{(\xi X}{N}\right)^{2}\left(E Y^{2}\right) \frac{(\xi Y}{N}\right)^{2}}}
\end{aligned}
$$

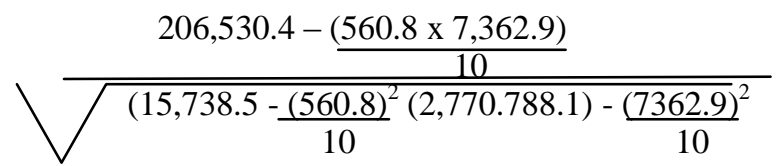

$$
r=206,530.4-4,129,114.3
$$$$
10
$$

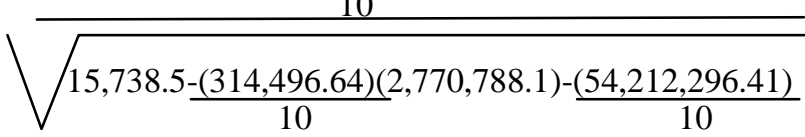

$=206.530 .4-412.911 .43$

$\sqrt{15,738.5-(31,449.664 \times 2,770,788.1)-5,421,229,641}$

$$
\begin{aligned}
& r=\frac{-206,381.032}{\sqrt{-871,45760250}} \\
& =\frac{-206,381.032}{-295,204.6074} \\
& =0.699 \\
& r=0.699 ; r 2=0.4886 \\
& 1-0.4886=0.5114=51.14 \%
\end{aligned}
$$

\section{B. Discussion}

The value of $r=0.699$ indicates a positive correlation between increase in temperature and malaria case in Orlu. This implies that $51.14 \%$ of malaria cases in Orlu area can be attributed to increase in temperature.

The results show a steady fluctuation in the temperature regime, which ranged from $27^{\circ} \mathrm{c}$, the least to $30^{\circ} \mathrm{c}$ the highest.

Malaria cases also increase from the least 305.1 recorded in 1991 to the highest level of 591.7 being the average in 2010. In 1992 average temperature reduced from $28^{\circ} \mathrm{c}$ to $27.3^{\circ} \mathrm{c}$ but malaria case increased from 305.1 to 327.1 . In 1993 temperature increased to $27.4^{0}$ and 
malaria cased increased to 362.3. 1996 and 1997, temperature was $28^{0} \mathrm{c}$ with malaria cases of 374.7 and 358.8 respectively, but in 1998 temperature increased to $28.4^{\circ} \mathrm{c}$ and malaria case increased from 358.8 to 373 . In 2004 , temperature rose to $30.7^{\circ} \mathrm{c}$ with malaria case 363.3 and the temperature dropped to $29^{\circ} \mathrm{c}$ in 2005 and 2006 with increase in malaria cases of 378.5 and 367 respectively. In 2007 the temperature dropped again to $27^{\circ} \mathrm{c}$ being the least in study period with also a decrease in malaria case of 358.3 , and finally in 2010, temperature increased to $28^{\circ} \mathrm{c}$ with sharp and highest increase in malaria case of 591.7, (Fig 1). It is seen from the results that both the increase and decrease in temperature can enhance malaria cases but generally the temperature has been warm and its steady increased encouraged more malaria cases that its decrease. Thus, "malaria is a disease of warm climates".

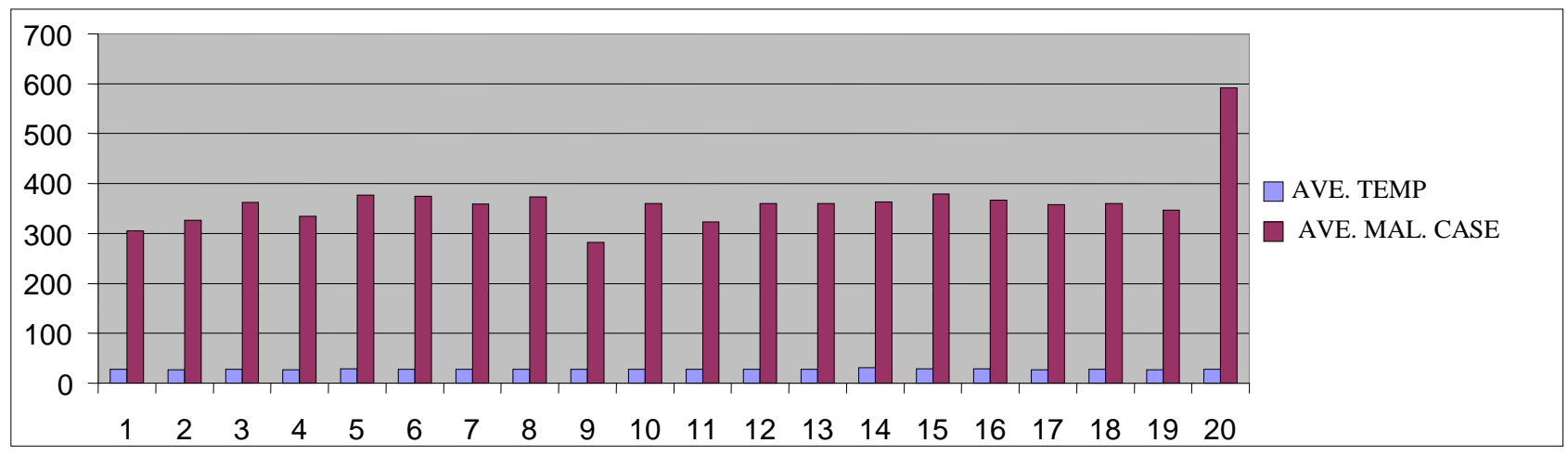

No of period in years ( 20 years)

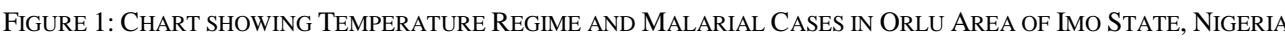

\section{CONCLUSION}

Malaria is a special threat to children, youth and women (particularly pregnant women) in places where it is common (e.g. Owerri municipal), and its present is attributed to climate variability and change, Okorie et al. [2012].

A good knowledge of global warming/global climate, which is in increase in temperature, and the impacts of such temperature increase on man's health in his environment, is of great importance and cannot be overemphasized.

This research however, established a positive correlation between increase in temperature and malaria cases. It shows that global warming and increase in temperature has enhanced the multiplicity and spread of malaria in Orlu area, and this trend of increment was observed in the annual average temperature of Orlu, which coincidentally, showed a marked increase in malarias cases with in the area from the year 1991-2010.

\section{RECOMMENDATION:}

In conformity with the Government of Nigeria ministry of health roll-back malaria programme, the following recommendations are made for proper cleanliness of surroundings and the entire environment to avoid mosquito breeding and thus, prevent malaria.

The inhabitants within Orlu and its' environs should be enforced to cut grasses and tidy up their surroundings at least once every week.

The inhabitants should also avoid storing dirty water in cans and buckets, as such are good breeding sites for mosquitoes.

Awareness should be created through regular seminars, workshops and conferences on the adaptation to climate variability, especially, increase in temperature and global warming.

The federal ministry of health should ensure regular documentation of up - to date information on malaria cases and other vector-born diseases to know the trend of occurrence, in order to advice the public on how to avoid the effects.

\section{ACKNOWLEDGEMENT}

This paper appreciates the efforts of Mr. Unaogu, the head, Roll Back Malaria Unit in Orlu Health Centre Headquarters of Imo State Ministry of Health in making data on malaria cases available for this research. Also, NIMET is appreciated for making weather data available always.

\section{REFERENCES}

[1] IPCC [2007].Impacts, Adaptations and Mitigation of Climate. Contribution of Working Group, 11 to the Second assessment of the IPCC. Cambridge University Press, 367:1792-1798.

[2] WHO, [2007]. Endemic malaria: an 'indoor' disease in Northern Europe. Historical data analysed, 2007. 4:19.

[3] WMO, [1995]. Cliamte change and health: global to local influences on disease risk; Ann Trop Med Parasitol, 100; 535-549.

[4] Okorie F.C., Okeke, I.C., Njoku J.D., Duru, P.N [2012], Climate variability and malaria incidence: Impact and Adaptation in Owerri Municipal of Imo State Nigeria, Advances in Education Research November 2012, San Degio, CA, USA, pp 98-104.

[5] UNICEF, [2009]. The - rise and fall of, Malaria in Europe. A historical - epidemiological study. Oxford: Oxford University, 15:105-111.

[6] National Population Commission, [2006]. Population census of the federal Republic of Nigeria, Abuja

[7] Snow, R.W., [2005]. Climate change: regional warming and malaria resurgence: nature 2005 , 420:627-628.

[8] Randall, [2007], Malaria risk and temperature: influences from global climate change and local land use practices. Proc Wat'L, Acad.Sci USA, 103:56355636. 